\title{
A busca de entendimento na confecção de material didático
}

\author{
Mariluce Filizola Carneiro Pessoa \\ Curso de Idiomas Ann Arbor, RJ.
}

\begin{abstract}
Resumo: O objetivo inicial deste trabalho era observar como um programa de curso de inglês, preparado por mim como supervisora, numa escola de ensino de línguas estrangeiras, poderia ser utilizado por professores não envolvidos na confecção desse material. O programa fora desenvolvido para alunos de nível pré-intermediário. Meu propósito era avaliar a eficácia desses planos de aula, porém o foco de minha investigação mudou no decorrer da pesquisa para ressaltar o entendimento que três professoras, que dão aulas a alunos desse nível, teriam de um programa preparado por terceiros. Procurei também buscar meu próprio entendimento no tocante à confecção desse material e à atividade de supervisão que desenvolvo junto a essas professoras.
\end{abstract}

Palavras-chave: prática pedagógica; Prática Exploratória; entendimento; cooperação; desenvolvimento mútuo.

\section{INTRODUÇÃO}

Para o desenvolvimento do trabalho, tomei por base a Prática Exploratória (PE), que "está sendo desenvolvida a fim de permitir um meio sustentável para promover entendimentos dentro de nossa prática pedagógica” (Allwright e Miller, 2001) ${ }^{1}$. Os autores, dez anos depois da criação da PE, ressaltam que a "Prática Exploratória está sendo desenvolvida”. Vejo nessa afirmação o reconhecimento de que uma abordagem pedagógica, pela sua própria natureza, está sujeita a novas descobertas e conseqüentes transformações no decorrer da própria prática. Eles dizem ainda que a PE está em desenvolvimento "a fim de permitir um meio sustentável para promover entendimentos”. Foi em busca desses entendimentos, para mim o princípio número um da $\mathrm{PE}$, que mudei o foco de minha pesquisa, tirando-o do material em si e passando-o para as pessoas envolvidas no processo educacional. O programa do curso, no entanto, serviu de base para o encaminhamento de minha investigação uma vez que o conteúdo a ensinar em uma determinada aula e como fazê-lo são preocupações fundamentais para um professor.

\footnotetext{
${ }^{1}$ As traduções dos textos originalmente em inglês serão feitas pela autora.
} 
Meu trabalho também foi pautado pela proposta de Moita Lopes (1996). Este autor, ao citar Edwards e Mercer (1987), distingue, no processo de construção conjunta de conhecimentos o conhecimento ritualístico ou processual e o conhecimento baseado em princípios. Esta distinção me fez entender que a mera observação do comportamento de alunos e professores durante uma aula, com o objetivo de tentar verificar a eficácia de um programa de curso, poderia estar me proporcionando apenas uma visão do conhecimento ritualístico das professoras e dos alunos. A fim de tentar entender se a prática pedagógica observada estava baseada em princípios, deveria conversar com as professoras para ver como elas entendiam o programa proposto e as decisões por elas tomadas. Portanto, realizei minha investigação assistindo a algumas aulas de três professoras que tinham turmas de nível intermediário, procurando ver como entendiam o material por mim preparado e tentando, eu mesma, entender não só o processo de confecção desse material, como também o papel que cada uma de nós desempenhava naquele trabalho. Foi a partir daí que teve início minha interação com as três professoras mencionadas acima.

\section{FUNDAMENTOS TEÓRICOS}

Em artigo sobre os fundamentos da Prática Exploratória, Allwright e Miller (2001) ressaltam a importância da relação entre "perceber” e "entender” e afirmam que nem sempre perceber significa entender. Um primeiro passo para o entendimento seria observar o que se passa no ambiente escolar como um todo. Só então, afirmam Allwright e Miller (ibid.), é possível destacar os aspectos do trabalho que parecem fluir suavemente e aqueles que causam problemas. Apontam os autores ainda para a necessidade de prestarmos atenção especial a esses aspectos a fim de chegarmos a um entendimento. Concluem: "Esperamos dessa forma compreender melhor o que se passa a nossa volta, entender nosso papel em todo esse processo e a repercussão que teria sobre a maneira como os colegas realizam seu trabalho" (Allwright and Miller, 2001). Baseei, então, minha pesquisa no primeiro princípio da PE, i.e.,o entendimento.

Dei prosseguimento a esse estudo tendo em vista dois outros princípios que dizem respeito à interação entre todos aqueles envolvidos na prática pedagógica: a cooperação entre colegas (collegiality) e o desenvolvimento mútuo. Este último propõe que se 
trabalhe para o desenvolvimento de todos os envolvidos na prática pedagógica enquanto que o primeiro estabelece que o trabalho se processe de modo a lidar com os desentendimentos entre professores e alunos, e entre professores e pesquisadores. Com base nesses princípios, busquei, junto a meus pares, insights relacionados à nossa função de educadores.

Alwright e Bailey (1991) afirmam que, no decorrer de uma aula, na interação entre professor e alunos, surgem oportunidades de aprendizagem - algumas que se originam do planejamento em si, e outras, de situações espontâneas criadas pelo grupo. Estava convencida de que a minha interação com as professoras e a nossa discussão do programa resultariam em reflexão, da parte delas, sobre as aulas que iriam ministrar e, de minha parte, sobre como procederia no planejamento daquele material. Assim, pautei meu trabalho fundamentalmente pelos princípios da Prática Exploratória do entendimento, collegiality e desenvolvimento mútuo.

Considero também importante registrar a diferença proposta por Moita Lopes (1996) entre conhecimento ritualístico ou processual e conhecimento baseado em princípio, quando ele afirma que o primeiro é “caracterizado pela procura da resposta certa [...], que se encaixa na estruturação discursiva de Iniciação-Resposta-Avaliação” e completa:

O outro tipo de conhecimento, isto é, o de princípio, está relacionado à compreensão subjacente ao conhecimento ritualístico, ou seja, é orientado para a compreensão de como o conhecimento processual funciona na aprendizagem em vez de ser visto como um tipo de conhecimento arbitrário, que fornece a resposta certa ao professor.

Ressalta ainda a capacidade do aprendiz de se distanciar daquilo que sabe e de refletir sobre seu próprio conhecimento. Tendo esse aspecto do processo de ensinoaprendizagem em mente, considerei muito mais relevante refletir junto às professoras sobre nosso entendimento em relação à maneira como os planos de aula seriam abordados do que verificar in loco a eficácia do programa.

\section{PROCEDIMENTOS}

O programa em desenvolvimento para o nível pré-intermediário tem por base o livro Inside Out, Pre-intermediate, da Macmillan, e foi elaborado de modo a detalhar o 
plano de cada aula a ser dada pelos professores em um semestre letivo, sugerindo atividades a serem desenvolvidas, exercícios extras a serem feitos pelos alunos e textos de leitura complementar com tópicos a serem discutidos em sala.

Inicialmente, assisti a duas aulas de uma professora, que, em geral, tem turmas de crianças do curso básico e de pré-adolescentes do curso pré-intermediário. O grupo era composto de quatro alunos, de idades entre 11 e 13 anos. A professora me recebeu cordialmente e com espírito de cooperação. Até então, meu contato com ela restringia-se aos momentos de reuniões da escola ou a eventos extracurriculares na instituição.

Assisti à primeira aula ainda com o propósito de ver se o material seria adequado aos alunos e se, de alguma forma, auxiliaria os professores. Para mim era importante receber o feedback da professora. Observei que, ao seguir o plano preparado por mim, alguns itens sugeridos para aquela aula haviam sido deixados de lado e outros, seguidos à risca. Um dos objetivos da aula era trabalhar as seguintes perguntas: "What is this city like?”; "What is the weather like?”; "What are the people like?”

No plano daquela aula, eu sugeria que o professor escrevesse no quadro essas perguntas e, a partir daí, eu propunha uma discussão entre os alunos. No meu entender, discutir características de cidades, principalmente de cidades conhecidas pelos alunos, poderia gerar uma discussão interessante. Pedi, então, no plano de aula, que fosse preparado um exercício de Language Analysis, o que, nessa instituição de ensino de línguas, pressupõe que os alunos, em círculo, discutam autonomamente o tema proposto, enquanto a professora, em geral fora da discussão, anota frases para serem analisadas na aula seguinte. Algumas dessas frases contêm os erros cometidos pelos alunos durante a discussão. A professora os anota e depois os categoriza, seja por problemas estruturais, seja por inadequações lexicais. Na aula seguinte, cada aluno recebe uma folha com as frases já agrupadas e são convidados a corrigir seus próprios erros com a ajuda dos colegas. Somente depois de a turma ter dado as possíveis soluções, a professora entra na discussão para ajudá-los com problemas não resolvidos. Frases bem elaboradas são igualmente anotadas pela professora e apontadas como boas soluções no uso da língua. A professora, no entanto, conduziu a aula com perguntas e respostas, porque a discussão em grupo não se deu, e o exercício em questão não foi preparado. 
Uma outra atividade programada para aquela aula, um exercício de Listening, foi feita como sugerida no plano de aula: os alunos escutaram o CD e depois responderam às perguntas sugeridas no livro. No momento em que a gravação foi apresentada aos alunos, considerei aquela atividade longa demais para pré-adolescentes. Observei que uma aluna, entre os três presentes, parecia alheia ao exercício, desenhando no caderno, o que parecia confirmar minha interpretação. Refletindo sobre a atividade, achei que eu deveria ter sugerido dividir o exercício em partes, levando em consideração a atenção exigida para uma atividade longa para alunos pré-adolescentes.

Um terceiro item daquela aula foi o uso de Count-Uncount Nouns. Para isso a professora lançou mão do material extra, encontrado no caderno de exercícios do aluno, sugerido no plano de aula. O tópico já era conhecido daquela turma, que havia aprendido a questão gramatical no nível anterior, e o desenvolvimento desse item da aula transcorreu como sugerido no programa.

Dois itens do plano de aula foram omitidos, uma música e o dever de casa. No final da aula, no entanto, a professora parecia satisfeita por ter cumprido o programa que colocara no quadro, no início. Os dois itens faltantes não constavam da programação que ela havia feito para aquele dia. No geral, a aula transcorreu em forma de diálogo entre a professora e os alunos, com pouca interação entre os colegas.

Marquei uma reunião com a professora para discutirmos o que eu havia observado. Até aquele momento, minha preocupação era saber por que algumas atividades não tinham transcorrido como propostas no plano de aula, por que tinha havido tão pouca interação entre os alunos e por que a discussão em grupo não ocorrera. Além disso, queria saber por que nem a música nem o dever de casa haviam sido dados como eu sugerira no plano de aula. Como fica patente, minha preocupação centrava-se no programa que eu havia preparado, muito mais do que como alunos e professores haviam entendido aquela aula.

Discuti o assunto com Inés Miller, professora e coordenadora de graduação da PUC-Rio, e disseminadora da Prática Exploratória. Na ocasião, eu fazia um curso sobre Linguagem e Ensino, ministrado por essa mestra. Ela me sugeriu pedir à professora que lesse comigo todos os itens planejados para aquela aula, dizendo como havia entendido minhas sugestões, em vez de perguntar por que esse ou aquele item do programa não 
havia sido coberto como planejado por mim. Até esse momento, minha preocupação era com o plano em si e com o trabalho que eu desenvolvera. Só mais tarde, vim a perceber que a orientação recebida me levava a mudar a ênfase da minha pesquisa e passar do plano de aula para o entendimento que a professora tivera daquelas sugestões feitas por mim. Aquela ocasião foi um momento de reflexão, que me fez entender o trabalho que eu estava realizando como supervisora e preparadora de material didático.

Uma semana depois, a professora e eu nos reunimos para discutir a referida aula, e procurei seguir a orientação de Inés Miller. Ao ser solicitada para dizer como entendia os itens de uma aula que já havia sido dada, a professora pareceu surpresa, mas o fez sem problemas. Vale notar que esse primeiro encontro se deu no ambiente descontraído de um Café. À medida que ela lia cada item, alguma observação era feita, às vezes por ela, às vezes por mim. Aproveitei para perguntar por que a música não havia sido dada, e ela prontamente respondeu que a fita estava defeituosa. Sobre o exercício de Listening, ao contrário do que eu pensava, ela disse não achar longo demais para os alunos e considerar que eles o teriam feito bem, pois haviam respondido a todas as perguntas. O dever de casa, por sua vez, não havia sido passado, porque os alunos teriam de entregar uma redação na aula seguinte. Ela fez algumas observações sobre os exercícios extras, dizendo que tinham sido apropriados para aquela turma. Admitiu, porém, que esperava que os alunos trabalhassem com mais autonomia, apesar de ter achado que a falta de interação podia ter sido por dois motivos: primeiro, porque fazia pouco tempo que estava com aquela turma, e os alunos ainda não estavam bem entrosados com ela; segundo, porque estava faltando uma menina, que parecia ser o elemento aglutinador da turma.

Depois daquela reunião, me fiz algumas perguntas: Como seriam entendidas pelo professor as sugestões de aula feitas por um supervisor? Até que ponto um plano de aula poderia ser seguido por um professor, principalmente quando não é ele quem programa suas aulas? No curso de idiomas onde trabalho, enfatiza-se sempre que o plano de aula sirva de orientação para facilitar a tarefa do professor e garantir o cumprimento de determinado conteúdo para cada nível. Entretanto, em busca de um entendimento, me perguntei se o professor, ao seguir um plano de aula preparado por terceiros, não deixaria passar as oportunidades espontâneas de aprendizagem. 
Continuando minha reflexão, combinei com a professora assistir a uma outra aula, duas semanas depois. Novamente, ela se dispôs a cooperar. Dessa vez, inverti o processo. No lugar de me reunir com ela depois da aula, me reuni antes, e ela foi me dizendo como entendia cada um daqueles itens. Havia sugestão de uma atividade chamada Poster Activity, na qual os alunos se reuniriam em pequenos grupos e fariam, em folhas de papel, frases com verbos no passado, usando o past simple e o past continuous. Depois, cada grupo colocaria sua folha no quadro e leria as frases e as corrigiria, caso fosse preciso. A professora imediatamente sugeriu um jogo e estabeleceu regras para pontuação dos grupos. Com sua concordância, assisti a essa aula, e a atividade transcorreu de forma interativa, com a turma toda envolvida.

Nesse mesmo dia, os alunos corrigiram o dever de casa e o fizeram de forma cooperativa e autônoma. Somente no final, a professora interferiu para esclarecer os pontos que não haviam ficado claros, mostrando que, embora ainda muito jovens, já eram capazes de negociar soluções. Como um todo, essa aula se deu de forma bem mais interativa do que a primeira. É também importante ressalvar que nesse dia estava presente a aluna que tem papel aglutinador na turma. Além disso, de acordo com o que a professora dissera, os alunos pareciam estar bem mais à vontade com ela na ocasião, pois já estavam juntos fazia um mês. A minha presença não pareceu afetá-los.

Não poderia dizer nesse ponto se alguma oportunidade de aprendizagem teria escapado à professora, mas ela certamente procurou seguir o programa como sugerido. Ter a presença de uma supervisora na aula pode levar o professor a ater-se ao planejamento e evitar qualquer alteração. Portanto, acredito, que as conversas que tivemos possam ter sido mais valiosas do que a satisfação de ter as aulas seguidas como programadas.

Dando procedimento a minha investigação, assisti a aulas de duas outras professoras. A primeira tinha uma turma de sete alunos, os quais interagiam bem, embora a professora achasse que eles fossem muito lentos, pois não conseguira acompanhar o programa. Pedi então à professora para me reunir com ela antes da aula, e ver como entendia o que fora proposto no planejamento para aquele dia. Nessa conversa, falamos sobre princípios em vez de nos concentrarmos no conteúdo em si. Quando discutimos o fato de ela estar atrasada com o programa, chegamos à conclusão de que as 
idiossincrasias de cada turma impediam que os programas fossem cumpridos à risca. Diante disso, perguntei se seria melhor não ter o planejamento em mãos para que ela preparasse as próprias aulas. A resposta foi que, apesar de não seguir o programa ao pé da letra, ela sempre se orientava por ele, o que, de certa forma, facilitava seu trabalho. Assisti à aula daquela turma e não a achei lenta como dissera a professora; certamente esse grupo tinha seu ritmo próprio e o programa teria necessariamente de sofrer alterações. Entretanto, omitir itens de um programa deixa as professoras tensas por saberem que têm de submeter os alunos a uma prova no final do curso. Para resolver esse problema, decidimos que ela prepararia, junto com a turma, uma questão para a prova, substituindo aquela que fosse inadequada para aquele grupo. Dessa forma, os alunos já estariam estudando o ponto por eles escolhido.

O diálogo que tive com a professora me rendeu momentos de reflexão sobre a confecção das aulas seguintes. Mais importante do que dizer como proceder diante de um determinado item lingüístico, seria deixar aberto um leque de oportunidades de aprendizagem a serem aproveitadas de acordo com a ocasião.

Para tornar possível esse entendimento, seria imprescindível que eu me reunisse algumas vezes com as professoras para trocarmos idéias sobre o programa. Decidi, então, assistir à aula da terceira professora. Dessa vez, tive muito pouco tempo para me reunir com ela antes da aula. Falamos apenas das questões que a preocupavam em relação à turma. Ela também achava seu grupo muito lento, por não conseguir acompanhar o programa proposto para o semestre. Demonstrava preocupação, porque um ponto gramatical inteiro havia sido deixado de lado. Dentro do sistema da escola, o remanejamento de alunos por questão de horário se torna problemático quando turmas de um mesmo nível não cumprem as exigências de um determinado programa. Isso e a questão da prova a deixavam bastante ansiosa em relação ao cumprimento do programa.

Quanto à prova, não houve problema, pois combinamos, como na turma anterior, que a professora refizesse as questões que achasse inadequadas para seus alunos. E quanto ao desnivelamento daquela turma em relação às outras, como o programa estava em fase de desenvolvimento, resolvi que reintroduziria o item não coberto por aquele grupo nas aulas do nível seguinte. 
Assisti à aula da professora naquele dia e verifiquei que suas quatro alunas realmente pareciam ter dificuldade de se expressar em inglês. Duas delas pouco falaram durante a aula. As negociações foram feitas em português, mas notei, pelas perguntas que faziam à professora, que todas demonstravam interesse e procuravam entender os princípios que regiam o uso do ponto gramatical abordado na aula. Após a aula, conversamos sobre os pontos que a preocupavam, agora que meu foco deixara de ser a realização do programa. Procurei saber se o silêncio das duas alunas poderia ter sido causado por minha presença. A professora disse que elas são tímidas e que, em geral, pouco participavam. O que observei, entretanto, foi que aquelas alunas pareciam interessadas, e que o silêncio delas não significava necessariamente falta de participação. Essa turma me deu a oportunidade de discutir com a professora a questão, proposta por Moita Lopes, da diferença entre um conhecimento que se dá de forma ritualística e um conhecimento baseado em princípios, ou seja, "orientado para a compreensão de como o conhecimento processual funciona na aprendizagem”. Enfim, aproveitei a ocasião para trocar idéias sobre o próprio processo de ensino-aprendizagem, como fizera com as outras duas professoras.

\section{CONCLUSÃO}

Minhas perguntas iniciais sobre o entendimento do professor, e o meu próprio, em relação ao material didático, se ainda não respondidas, pelo menos passaram a me dar uma visão melhor do trabalho em que estou envolvida. Acredito que a atividade pedagógica como um todo está em permanente processo de desenvolvimento; por isso, não acredito poder obter respostas imediatas a essas perguntas. Mas alguns pontos podem ser ressaltados.

Primeiro, ao procurar observar o entendimento das professoras envolvidas neste trabalho, cheguei à conclusão de que mais importante do que saber se um plano de aula está sendo cumprido é saber como o professor vê o material que tem em mãos e que mudanças propõe fazer.

Segundo, ao analisar a execução de um plano de aula desenvolvido por terceiros, observei que ele pode servir de guia para alguns professores, mas certamente sofrerá tantas transformações quantas forem as pessoas envolvidas nesse trabalho. 
Finalmente, tenho a convicção de que é mais eficaz discutir com os professores os princípios que regem o ensino do que simplesmente procurar ver se um plano está sendo seguido ou não. A mudança de foco desse estudo, passando-o para o aspecto humano do trabalho, deixou patente a importância do trabalho cooperativo entre os participantes da atividade pedagógica, sejam eles alunos e professores, sejam professores e supervisores. Na busca de entendimentos, descobrimos juntas a importância da cooperação entre colegas e a promoção do desenvolvimento mútuo.

\section{Referências bibliográficas}

Allwright, D. \& Bailey, K. (1991). Focus on the Language Classroom: An Introduction to Classroom Research for Language Teachers. Cambridge: Cambridge University Press.

Allwright, D. \& Miller, I. (2001). Bringing Work 'to Life': Exploratory Practice for the Language Classroom. In www.letras.puc-rio.br/epcentre

Edwards, D. \& Mercer, N. (1987). Common knowledge: the development of understanding in the classroom. London: Methuen.

Moita Lopes, L. P. (1996). Interação em Sala de Aula de Língua Estrangeira. Oficina de Lingüística Aplicada, 95-107. Campinas, São Paulo: Mercado das Letras.

\section{A AUTORA}

Mariluce Filizola Carneiro Pessoa é professora de inglês e supervisora no Curso de Idiomas Ann Arbor, no Rio de Janeiro. É também tradutora formada em Letras Português-Inglês, com habilitação em Tradução, pela Pontifícia Universidade Católica do Rio de Janeiro, onde atualmente cursa o mestrado em Estudos da Linguagem.

E-mail: marilucepessoa@globo.com 